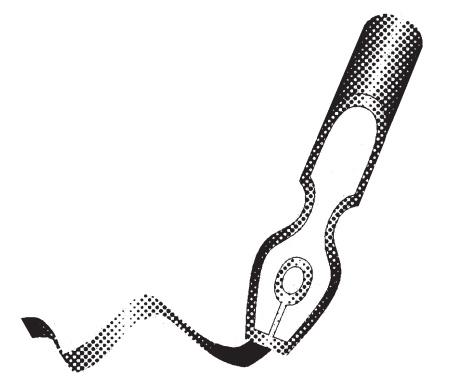

\title{
Datos y sugerencias para la Revista
}

Estimados miembros de la Sociedad Chilena de Otorrinolaringología, Medicina y Cirugía de Cabeza y Cuello y otorrinos de países que publican. Nuestra revista enfrenta durante este año 2016 nuevos desafíos y lo hace con renovadas energías. En ese contexto Uds. verán que el número que tienen en su poder, es más voluminoso de lo habitual, lo que representa el gran interés que existe en publicar en ella.

El Comité Editorial durante el año 2015 ha debido trabajar más intensamente que en años anteriores y ponemos a su consideración algunas cifras estadísticas disponibles, que indican que hemos recibido trabajos de 15 países excluido el nuestro, mayoritariamente de España, México, Colombia y Argentina. Nuestra publicación es cuatrimestral y durante el año 2015 el número de trabajos publicados fue de 11,16 y 16, respectivamente. El promedio de días entre la fecha del ingreso de un trabajo y la fecha de aceptación de publicación fue, durante este periodo, de 98,2 días.

Este número, el primero de este año, tiene 18 artículos y 150 páginas. El número de artículos objetados por el editor y el cuerpo editorial fue de 21 y 8 por los correctores; muchos de los cuales, fueron nuevamente reenviados al cumplir con las instrucciones para los autores publicadas en el sitio web de nuestra sociedad (www.sochiorl.cl).

Durante el año 2015 hemos perfeccionado la identificación de los autores privilegiando el lugar de realización del artículo en referencia y no los diferentes lugares de trabajo del autor.

Al momento de escribir este editorial ya tenemos aceptados nueve trabajos para el número de agosto 2016.

Todo lo logrado ha sido el esfuerzo conjunto de los editores asociados, de los editores y correctores y principalmente por el adecuado uso de nuestra plataforma electrónica. En base a todo lo anterior y considerando lo útil y necesario que sería aumentar a 4 números al año, haremos una encuesta ONLINE a nuestros asociados, para conocer cuál es el real parecer de la aceptación de la revista y de 
las sugerencias que allí se plantearán. La respuesta de esta consulta será de gran valor ya que nuestro trabajo necesita de la retroalimentación de nuestros lectores y principalmente de los socios para cumplir con la premisa que nos convoca en sentido de realizar un incremento real al quehacer científico de la Sociedad ORL de Chile.

Dr. Jorge Caro Letelier 